\section{Social inhibition of territorial marking in the Mongolian gerbil (Meriones unguiculatus)*}

\author{
JOHN NYBY, D. D. THIESSEN, and PATRICIA WAL LACE \\ University of Texas, Austin, Texas 78712
}

Male gerbils were tested for marking frequency in a residents' territory over a number of days. Experimental animals were allowed contact with residents immediately after each marking trial; control animals were not. Animals exposed to residents eventually decreased their marking to about $25 \%$ of control males; however, marking was reestablished in novel territories. Olfactory cues from residents or other intruding males depressed marking. Visual and auditory cues were ineffective. Moreover, odors from the residents" colony were avoided in a Y-tube preference test. Autopsies revealed no evidence for androgen inhibition or stress effects. Evidently, gerbils are territorial and defend their claims primarily by olfactory intimidation.

The Mongolian gerbil (Meriones unguiculatus) marks low-lying objects in its environment by rubbing them with a midventral sebaceous scent gland. The behavior deposits a musky-smelling sebum which is oily to the touch. The marking behavior, as well as the size of the scent gland, are sexually dimorphic, with the male marking territories twice as frequently as the female and having approximately twice as large a gland (Thiessen, Blum, \& Lindzey, 1970). The marking response can easily be quantified by scoring the animals in an open field in which small rectangular pegs are attached to a flat floor at regular intervals (Thiessen, 1968). Marking is confined almost entirely to the pegs and is characterized by a slight spreading of the hind legs, coupled with a lowering of the ventral surface as the gerbil moves over the peg. The marking behavior, as well as the scent-gland integrity, are androgen dependent in the male. However, the gland is maintained by the hormone acting peripherally, while the behavior is controlled centrally (Blum \& Thiessen, 1970; Thiessen \& Yahr, 1970).

Although much research has been done on hormonal control of marking behavior, little evidence has accumulated concerning the functional significance of this behavior. Some of the available evidence suggests that the behavior has territorial significance. Low but significant correlations have been found between gerbil seminal vesicle weight, measure of androgen titer, marking, and dominance (unpublished). The fact that both marking

*This investigation was supported by Grant MH 14076-03, Research Scientist Development Award MH 11, 174-03 to D. D. Thiessen from the National Institute of Mental Health and Biomedical Sciences Support Grant FR-07091-05 from the General Research Support Branch, Division of Research Resources, Bureau of Health Professions, Fducation and Manpower Training, National Institutes of Health. and aggression appear to be controlled by androgen titer lends credence to the idea that marking behavior has a territorial function. It has also been found that if a low-marking animal establishes dominance over a high-marking animal by defeating him in a fight, the low-marking animal shows a dramatic increase in marking frequency, while the high-marking animal shows a comparable decrease (unpublished).

The studies reported in this paper examine additional relationships that are predicted for a territorial animal. First, gerbils that have matured in a territory are expected to defend it against intruders. Second, intruders should be at a disadvantage and reduce their territorial behavior. Third, intruders should recognize their hosts' territory on the basis of relevant sensory cues and, when possible, avoid these. Several observations bearing on these issues are reported here.

\section{METHOD}

Animals and Apparatus

Two litters of six males and five females served as resident animals. They were raised from 1 week of age in a double-compartment box, $125 \mathrm{~cm}$ long $\mathrm{x}$ $62.5 \mathrm{~cm}$ wide $\times 72 \mathrm{~cm}$ high and were approximately 100 days of age at testing. The compartments of the residents' box were connected by a $7.5-\mathrm{cm}^{2}$ Plexiglas guillotine door. While both compartments served as home territory for the 11 gerbils, only one compartment contained marking spaced black Plexiglas pegs were $2.6 \mathrm{~cm}$ long $\times 1.2 \mathrm{~cm}$ wide $\times 0.7 \mathrm{~cm}$ high. The adjoining compartment contained a small plastic cage with a hole in its side as a shelter for the colony animals. Water and Purina Lab Chow were provided ad lib throughout the study. Illumination was provided by a $15-\mathrm{W}$ fluorescent lamp hanging approximately $1 \mathrm{~m}$ above the floor of the living community. A dark-light cycle pegs on the floor. The four regularly of 12D-12L was maintained. A black grid with squares $16 \mathrm{~cm}^{2}$ was panted on the floor of the marking compartment to assess general activity.

The "intruding" gerbils were 14 adult males less than a year old. All had been used in other behavioral studies unrelated to this study. Each male was housed with a female in a plastic cage measuring $10 \times 13 \times 25 \mathrm{~cm}$, in which water and Purina Laboratory Chow were provided ad Jib. Each had been assessed for marking frequency three limes during one $7-\mathrm{min}$ and two 5-min periods in the residents' box, but with the residents confined in the adjoining side. On the basis of these scores, two matched groups of seven each were formed. Group 1 was termed interaction group (IG) and Group 2 was termed noninteraction group (NIG).

Several other apparatuses were used in later phases of this experiment. The first was a black Plexiglas marking box, $26 \mathrm{~cm}^{2}$ with $20-\mathrm{cm}$-high walls. At the bottom of one wall the black Plexiglas was replaced by a $6.6-\mathrm{cm}$-high strip of clear Plexiglas which allowed observation of marking from the side. Six white Plexiglas pegs, $2.5 \mathrm{~cm}$ long $\times 1.5 \mathrm{~cm}$ wide $\times 0.5 \mathrm{~cm}$ high, were attached to the floor at regular intervals. Lighting was provided by a $20-\mathrm{W}$ fluorescent bulb $1 \mathrm{~m}$ above the floor of the box.

A Plexiglas Y-tube apparatus was used to assess olfactory preferences. The $Y$-tube had three $39-\mathrm{cm}$ arms of transparent tubular Plexiglas with an outside diameter of $7 \mathrm{~cm}$. One arm connected to a detachable startbox, while the other two arms were connected to detachable goalboxes. All boxes measured $13 \times 16 \times 17 \mathrm{~cm}$. A variable-speed fan was used to draw airborne odors from the goalboxes through the Y-tube and into the startbox. Animals were run under room fluorescent lighting.

\section{Procedure}

The experiment was conducted in six phases. Each was conducted in such a way as to determine, at least in part, the kinds of sensory stimuli regulating marking behavior of intruders in a strange territory.

Phase $A$ of the experiment began when the colony animals had reached approximately 100 days of age. Both IG and NIG animals were given 10 daily marking trials in the colony box. A marking trial consisted of placing an individual gerbil in the marking compartment of the colony box, with the resident animals restrained in the adjacent compartment, and counting the number of marks by the intruder during a 5-min period. For an IG animal the guillotine door was opened immediately following the 5-min test period, and the residents 
allowed into the marking compartment. A 3-min interaction period occurred; however, if fighting became too violent, the intruder was removed before the end of $3 \mathrm{~min}$. For an NIG animal, the guillotine door remained shut, and the animal remained in the box an additional $3 \mathrm{~min}$ beyond the marking trial. The box was not cleaned during the 10 daily trials. When it became apparent that activity might be related to marking frequency, raises on hind legs were recorded for Trials 3 through 9 and line crossings were recorded on Trial 10.

In Phase B of this experiment the effects of testing IG and NIG animals in an apparatus different from the colony's residence was assessed. The IG and NIG animals were individually given two $5 \cdot \mathrm{min}$ trials on successive days in the black marking box. The apparatus was cleaned with a 95\% ethanol solution before the start of each trial. Resident animals did not occupy this box, and no social interaction followed the marking test. Animals were tested 2 days after Trial 10 of Phase A.

Phase $\mathrm{C}$, as well as the subsequent phases, followed within 2 days of each other. Phase $\mathrm{C}$ consisted first of two trials for each intruder, using the same procedure employed in Phase A. The resident animals were then removed and the colony box cleaned thoroughly and IG and NIG given two additional 5-min trials in the marking compartment. For these last two trials, no social interaction followed the marking tests and the box was cleaned only at the end of each day's testing.

The procedure for Phase D was identical to that of Phase $\mathrm{C}$, with the exception that on the last two trials the marking compartment was cleaned after each animal had been scored.

Phase $\mathrm{E}$ again consisted first of two trials in the marking compartment, using the procedure of Phase A. During the 5-min marking trials a tape recorder was used to record the sound of resident gerbils scratching at the guillotine door and walls of the colony box. The IG and NIG were then given two more 5-min marking trials without social interaction in the black marking box with the tape recorder playing back the colonys' sounds. The box was cleaned after each animal was tested.

In Phase F the IG and NIG individuals were given two 5-min trials without social interaction in the black marking box in which sawdust, fecal boli, and other contaminants from the colony box were spread thinly over the floor. The box was not cleaned between animals.

Following this sequence of testing, IG and NIG animals were given two trials in the Y-tube apparatus. One of the goalboxes contained shavings taken from the gerbil's

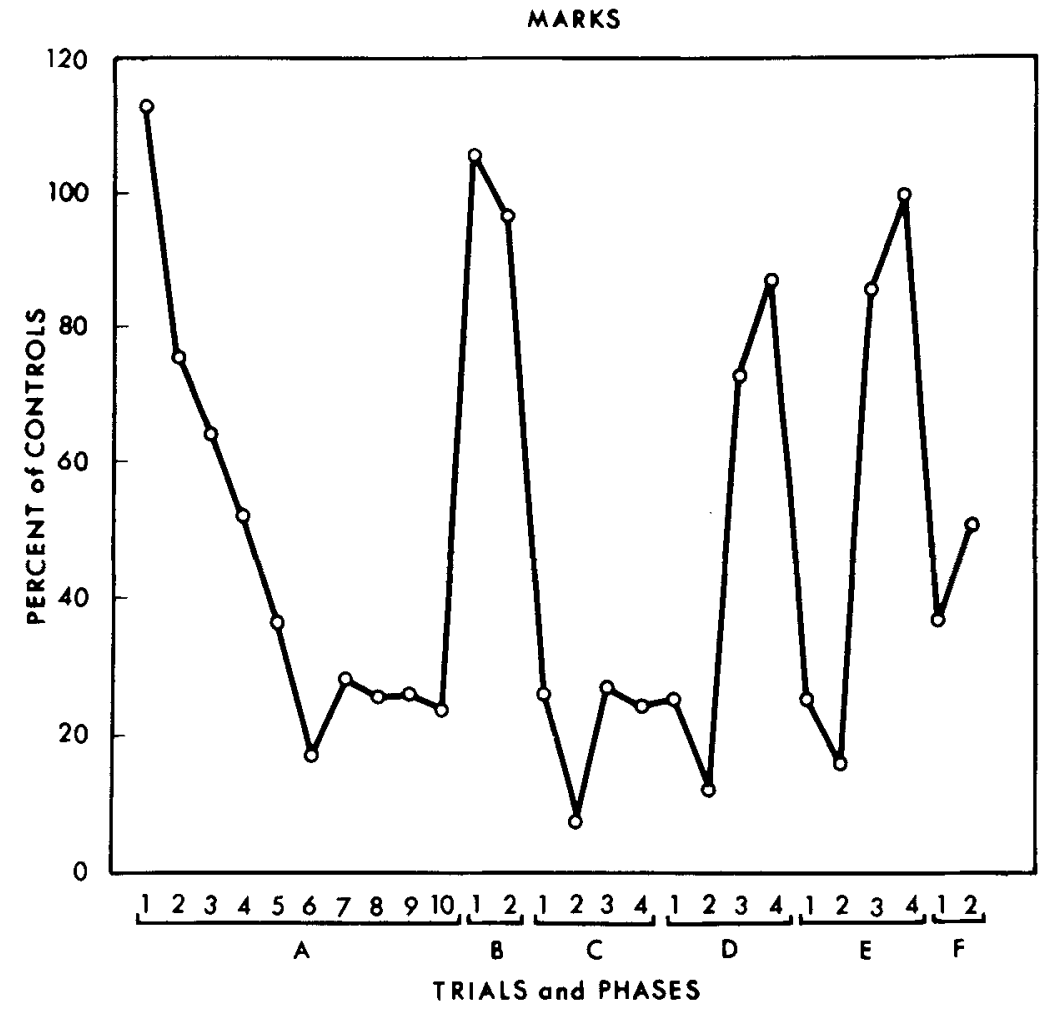

Fig. 1. Effects of social interaction and sensory cues on marking frequency of gerbils.

home cage, while the other contained the same amount of shavings from the living compartment of the colony box. The gerbils were allowed free movement throughout the $Y$-tube for $5 \mathrm{~min}$ and the amount of time spent in each of the two goalboxes was recorded. The goalboxes were alternated between trials. The tube and startbox were cleaned after each animal's trial.

Finally, IG and NIG animals were weighed to the nearest $0.1 \mathrm{~g}$ and a preweighed filter paper strip rubbed across the scent gland to assess the amount of scent gland secretion. The strips were reweighed to the nearest $0.1 \mathrm{mg}$. The animals were then sacrificed and the following organs removed and weighed to the nearest $0.1 \mathrm{mg}$ : testes, seminal vesicles, spleen, and adrenals.

In summary, the only difference between IG and NIG animals was that IG animals were given exposure to the residents. IG animals were exposed to residents in Phase $A$, to a clean and novel apparatus in Phase B, to odors from other intruders but not residents in Phase $\mathrm{C}$, to a clean colony compartment in Phase $\mathrm{D}$, to sounds from residents in a clean unoccupied box in Phase E, and finally to the contaminants of residence in an apparatus other than the colony box in Phase F. The sequential manipulations involve physical contact, sensory novelty, physical contact, odors associated with physical contact, physical contact, olfactory novelty, physical contact, auditory signals from residents and odor contaminants from residents. Body weights, scent gland smears, and organ weights were assessed to determine if androgen secretion was modified by social interaction or if physiological stress was evident.

\section{RESULTS}

Marking was initially the same for IG and NIG animals $(\vec{X}=15.6 \pm 2.74$ and $15.9 \pm 3.85$, respectively). However, as shown in Phase A of Fig. 1, animals receiving interactions with the colony steadily decreased their marking frequency to about $25 \%$ of NIG gerbils. NIG animals continued to mark at a mean frequency of approximately 15 marks per 5 -min trial throughout all phases of this experiment. A matched-groups analysis of variance across all 10 trials indicated that the two groups were significantly different in marking frequency $(\mathrm{F}=11.7 ; \mathrm{df}=1 / 6 ; \mathrm{p}<.02)$. The number of raises on hind legs and line crossings were not significantly different in the two groups.

As can be seen in Phase B, when the IG gerbils were tested in a clean unfamiliar apparatus, they returned to preinteraction levels of marking. The IG and NIG animals 
did not differ significantly for these two trials.

Trials 1 and 2 of Phase $C$ indicate that the IG animals marking frequency was again depressed when tested in the colon! box in the usual way. The depression was significant using a two-tailed test $(\mathrm{t}=4.13: \mathrm{df}=13: \mathrm{p}<.01)$. The depression in marking was apparent after the resident animals were removed and their olfactory cues eliminated by cleaning $(t=3.42$ : $\mathrm{df}=13: \mathrm{p}<.01)$. Odors from other $\mathrm{IG}$ and VIG animals remained, however.

During Trials 1 and 2 of Phase D. when residents and their odors were in the colony box. marking was significantly depressed $(\mathrm{t}=2.42: \quad \mathrm{df}=13 ; \mathrm{p}<.05)$ : however. during the next two trials, when both resident and intruder olfactory cues were removed by cleaning after scoring each animal. the IG animals rebounded to approximately $80 \%$ of NIG. The difference between $\mathrm{IG}$ and $\mathrm{NIG}$ groups at this point was not significant.

Returning the resident animals to the colony box and allowing social interaction after the marking trial resulted in a significant depression of marking on Trials 1 and 2 of Phase $E(t=2.93: \mathrm{df}=13$ : $p<.02)$. However, when the NIG and IG were tested in the black marking box on Trials 3 and 4 with the tape recorder playing colony sounds, the IG animals marked at a high frequency not significantly different from NIG gerbils.

As indicated for Phase $F$ in Fig. 1, the colony shavings depressed marking frequency in the IG animals. even in a novel marking apparatus. The difference between groups was significant $(t=2.87$; df $=13 ; \mathrm{p}<.02)$.

The Y-tube olfactory preference was calculated by subtracting the time spent in one goalbox of the Y-tube from that of the other. The IG animals spent much more time in the goalbox containing their own home shavings. while the VIG spent approximately equal time in both goalboxes. This difference was significant $(\mathrm{t}=2.42 ; \mathrm{df}=13 ; \mathrm{p}<.05)$. In other words, IG gerbils either preferred their own odors or avoided those of resident animals.

The two groups did not differ significantly in body weight or gland smear weight, or in testis, seminal vesicle, spleen, or adrenal weights.

\section{DISCUSSION}

It was immediately apparent that gerbils defend territories in which they have grown up. Fights between the resident and IG animals occurred on almost every interaction test. The resident animals were invariably the aggressors. Often two or three resident animals would mob the intruder. but even in fights involving onl one resident the resident always emerged victorious. in spite of the fact that most IG males were older and bigger than the resident animals. The intensity of these attacks increased as the testing progressed. In many cases IG animals had to be removed before the 3 -min interaction had ended to escape major injury or death. The colony animals were never observed to fight among themselves except for apparent cases of mistaken identity. These fights were rapidly terminated. Somewhat surprisingly. the female resident animals seemed as aggressive as the males.

Fights were often preceded by "boxing" or "sidling" behavior. Boxing consisted of the two opponents standing on the ir hind feet, nose to nose. and pawing at each other with their front legs. The sidling behavior was engaged in mainly by the IG gerbils and consisted of one animal's reacting to the advances of the other by bending the side of his body in a concave manner and pushing this side against the other animals.

Clearly, intruders entering into an established colony decrease their frequency of marking as a result of lost encounters. The marking reduction in the $\mathrm{IG}$ animals cannot be explained in terms of short-term emotional reactivity since the time between an interaction and marking trial was approximately 1 day. Neither can the marking reduction be explained in terms of activity levels since the number of line crossings and hind-leg raises were not significantly different in the two groups. The marking decrement cannot be readily explained in terms of lowered androgen levels, since there were no group differences in seminal vesicle, testis, or gland smear weights. Finally, physiological stress was not evident in the weights of the adrenals or spleen. As Phase B indicates. the marking decrement exhibited by the IG animals was specific to the colony box and was not a generalized loss of marking capacity. Apparently adverse social interactions in a strange environment can lead to reversible decreases in marking frequency. Unfortunately, no data are available on the marking performance of our resident animals, since they were too young to display reliable marking frequencies. Other unpublished data suggest, however, that dominant animals increase their marking frequency in competitive situations.

In general it appears that gerbils learn to inhibit mathing in a strange temitory by attending to olfactory cues associated with defeat. Neither visual cues from a novel enviromment (Phase B) or from the residents territory (Phase D) alter marking independently of olfactory cues. Auditory stimuli from resident animals are equally ineffective (Phase E). Olfactory cues from territorial owners, however, can depress marking in defeated animals even when the visual configuration of the environment is altered (Phase F). Olfactory sensitivity also extends to contaminants from other defeated and undefeated intruders (Phase C). Hence, a defeated animal discontinues territorial behavior in the presence of olfactory cues from all animals. whether dominant territorial owners or not. that are associated with his defeat. This multiple inhibition presents the interesting idea that social orders are stable because of multiple odor sources and can be maintained in the temporary absence of dominant individuals.

The relative avoidance of odors from resident animals by defeated males was demonstrated for a second time in the $Y$-tube experiment. Apparently the effects of social status can generalize to any situation in which odors can be detected.

The overall results of the experiments clearly demonstrate that gerbils actively defend territories and are likely to win over intruders. Intruders learn to avoid territorial behavior on the basis of odor cues. In no obvious way is marking capacity destroyed, however, and the discontinuance of marking is a stimulus-bound repression.

\section{REFERENCES}

BLLIF. S. L. The androgen control of scent marking in the Hongolian gerbil (Meriones unguiculatus). PhD dissertation. Lniversity of Texas. 1969.

BLL.I. S. L.. \& THIESSEN. D. D. The effect of ventral gland excision on scent marking in the male Hongolian gerbil. Journal of Comparative \& Physiological Psychology, 1970, in press.

THIESSEN, D. D. The roots of territorial marking in the Mongolian gerbil: A problem of species-common topography. Behavior Research Methods \& Instrumentation, 1968.1, 7076.

THIESSEN, D. D., BLC.I. S. L., \& LINDZEY. G. A scent marking response associated with the ventral sebaceous gland of the Mongolian gerbil (Veriones unguicularus). Animal Behaviour, $1970,18,26-30$.

THIESSEN. D. D.. \& YAHR. P. Central control of territorial marking in the Mongolian gerbil. Physiology \& Behavior, 1970, 5, 275-278. 